\title{
Chapter 10 \\ Proximity, Social Capital and the Simon Model of Stochastic Growth
}

\author{
Koen Frenken
}

\subsection{Introduction}

It is customary to define economic geography as a discipline that deals with the uneven distribution of economic activity across space. From a historical perspective, stochastic growth models are of particular use (Simon 1955). Such models explain the current distribution of activities from the dynamics of the long historical process that has produced these patterns. This approach might also be labelled "evolutionary economic geography" (Boschma and Frenken 2006), referring to the evolutionary economics tradition, since stochastic growth models account for path dependence in which each event changes the probability of a next event to occur (Arthur 1989; David 1985).

In geography, stochastic models of urban growth have a long intellectual history. In particular, The Simon model of the Zipf's rank-size rule is still regarded as one of the canonical models of urban size distribution (Batty 2005). A shortcoming of these urban growth models is that they take spatial entities as the unit of analysis. Since spatial entities are not behavioural entities, the explanation of urban growth in such models is not grounded in the micro-behaviour of agents. What is more, the delineation of spatial entities is a notoriously difficult exercise. Organizational units are less problematic, because these are the agents of change and relatively easy, though by no means trivial, to delineate. More recently, some of the urban growth models have explicit micro-foundations, including neoclassical models (Duranton and Puga 2004) and agent-based models (Batty 2005).

It is for these reasons that scholars have turned to micro-founded theories. One such attempt has been to take product divisions as the unit of analysis and define growth as stemming from product innovations leading to new product divisions within an existing firm or a new firm, and within an existing city or a new city.

\section{K. Frenken}

Urban and Regional Research Centre Utrecht (URU), Faculty of Geosciences, Utrecht University, Utrecht, The Netherlands 
Reasoning from product divisions allows us to model the firm size distribution and the city size distribution simultaneously (Frenken and Boschma 2007). It also allows to model social networks emerging from the mobility decisions of entrepreneurs moving between product divisions within or between firms, and within or between cities. The structure of these networks can be analysed using a spatial interaction equation as to analyse what types of "proximities" affect the interdependencies between cities and between firms. In this way, we can understand the formation of higher order entities, particular business groups and city-regions, as a logical "multilevel" outcome of stochastic growth models.

\subsection{Industrial Dynamics and Urban Growth}

City size distributions are well approximated by Zipf's law, which states that the size of the $n$th ranked city is $1 / n$ times the size of the largest city (Zipf 1949). To understand this distribution as the result of a historical growth process, Simon (1955) modelled city growth by discrete increments (lumps). The probability that a city receives this lump is proportional to its size and with some small probability the lump can create a new city. Having the latter probability approach to zero, the resulting distribution will be Zipf distributed. Notwithstanding the limitations, Simon's model provides a useful analytical starting point in thinking about uneven distributions in geographical space for two reasons. First, the model performs remarkably well empirically and is extendable as to account for more specific empirical outcomes. Second, the model is, in essence, an evolutionary model in that the probability of a particular event to occur is affected by the events that have taken place in the past (path dependence).

The model, however, lacks micro-foundations as urban growth is modelled as stemming from exogenous lumps rather than from agents' decisions. From an evolutionary perspective, reasoning from spatial units makes it difficult to introduce explicit firm dynamics into a theoretical framework (Boschma 2004). Yet, firm dynamics ultimately drive economic growth through the diffusion of routines in the economic system. An evolutionary approach to economic geography can thus build on a demographic perspective, which focuses on changing spatial patterns resulting from entry, growth and exit of firms, or as in the discussion below, on birth processes alone.

Reasoning from firms, we take product divisions as the unit of analysis, where each division belongs to a particular firm and is located in a particular city. One can then derive the firm size distribution by aggregating product divisions into firms and the city size distribution by aggregating product divisions into cities. In this framework, firm growth and urban growth occur simultaneously through the establishment of new product divisions, where the size of a firm or a city is simply defined as the number of product divisions belonging to a firm or a city, respectively. In terms of Simon's model, the lumps that drive growth can be considered as product innovations that are exploited by entrepreneurs by establishing a new 
product division. By reformulating Simon's stochastic model as a growth process fuelled by new product divisions, and by assigning each new product division simultaneously to a firm and a city, the firm size distribution and the city size distribution can be derived from one single growth process.

Following Frenken and Boschma (2007), one can introduce two organizational parameters ( $p$ and $p^{*}$ ) and two locational parameters ( $q$ and $q^{*}$ ). With probability $p$ the employee will commercialize the innovation in-house leading to a new product division within the parent firm. With probability $p^{*}$ the employee will commercialize the product innovation in another firm by changing jobs. The remaining probability $\left(1-p-p^{*}\right)$ is the probability that the employee creates a spinoff firm (which, following the Simon model, should be very small). And, with probability $q$ the innovation will be commercialized in the city of origin. With probability $q^{*}$ the innovation will be commercialized in another city. And with the remaining probability $1-q-q^{*}$ the innovation will be commercialized in a new city (which, again, should be very small). The probabilities can be multiplied since organizational and locational events are orthogonal to each other. For example, a firm can grow internally $(p)$ but at a different location than the division from which the idea originated $\left(q^{*}\right)$ or even at a new location $\left(1-q-q^{*}\right)$.

This reformulation of Simon's model incorporates nine possible events resulting from a product innovation (see Table 10.1). As such, the framework provides a rich repertoire for formal modelling approaches with only four parameters $\left(p, p^{*}, q\right.$ and $\left.q^{*}\right)$. Firms and cities being the aggregates of product divisions, the model will produce the Zipf law for both the firm size distribution and the city size distributions in a single model as long as (Frenken and Boschma 2007):

1. $\left(1-p-p^{*}\right)$ and $\left(1-q-q^{*}\right)$ are close to zero and

2. In case of inter-firm or inter-city mobility, the probability that an employee chooses a firm or city, respectively, is proportional to its size (otherwise growth ceases to be proportional to size).

It is the latter assumption that we loosen in the following to account for biased mobility patterns. The bias we assume comes from the social networks of inventors who have previously worked together in a product division. As a result, we obtain correlated growth rates between "networked" firms and cities, which we elaborate in the form of hypotheses for future empirical research.

Table 10.1 Possible events resulting from a product innovation

\begin{tabular}{ll}
\hline$(p)(q)$ & Internal firm growth in city of origin \\
$(p)\left(q^{*}\right)$ & Internal firm growth in another city \\
$(p)\left(1-q-q^{*}\right)$ & Internal firm growth in a new city \\
$\left(p^{*}\right)(q)$ & Firm growth though labour mobility in city of origin \\
$\left(p^{*}\right)\left(q^{*}\right)$ & Firm growth though labour mobility in another city \\
$\left(p^{*}\right)\left(1-q-q^{*}\right)$ & Firm growth though labour mobility in a new city \\
$\left(1-p-p^{*}\right)(q)$ & Spinoff in city of origin \\
$\left(1-p-p^{*}\right)\left(q^{*}\right)$ & Spinoff in another city \\
$\left(1-p-p^{*}\right)\left(1-q-q^{*}\right)$ & Spinoff in a new city \\
\hline
\end{tabular}

Source: Frenken and Boschma (2007) 


\subsection{Proximity}

Mobility patterns of employees setting up their own product division create links between divisions. Since the Simon logic prescribes that each existing division has the same probability to give birth to an entrepreneur as any other division, the resulting network structure between divisions in the Simon model will be a perfect tree. Starting from the first product division in the economy, a new entrepreneur is added to the network at random. Each new division is connected through the parent division by a link. And, since division give birth to new division randomly, the resulting structure is a simple random tree where the degree of each node will be proportional to its age.

The tree-like network structure between divisions can be aggregated at the level of firms and at the level of cities. Note that this aggregation yields a network structure including intra- and inter-organizational links and intra- and inter-city links, respectively. The aggregated network structure at the level of firms or cities will be different from the random tree obtained at the level of product divisions as long as $\left(1-p-p^{*}\right)<1$ and $\left(1-q-q^{*}\right)<1$. If not, all new product divisions would lead to new firms and new cities, and the aggregated network at the level of firms and at the level of cities would yield the exact same network structure.

In the model, we have mobile agents between firms in case $p^{*}>0$ and mobile agents between cities in case $q^{*}>0$. In these cases, one has to specify the choice behaviour of entrepreneurs. The assumption proposed by Frenken and Boschma (2007) is to assume that the probability that an employee chooses a particular firm and city is proportional to their size as to ensure that the proportionate growth feature of the Simon-model is replicated. This assumption is equivalent to random interaction models, which state that migration flows between entities are proportional to their size ${ }^{1}$ (Pumain 2006, p. 202).

The assumption of random interaction is obviously too crude, as mobility patterns are influenced by macroscopic structures. Labour mobility does not take place randomly; rather, most people move within the firm, or between firms whose activities are organizationally coordinated. One can measure the extent to which two organizations are tied by coordination, also called organizational proximity (Boschma 2005), for example, in terms of co-ownership or interlocking corporate boards. Thus, one can expect the probability of someone setting up his or her new product division in a particular firm to be dependent on the organizational proximity between the sending firm and the receiving firm.

Similarly, mobility between cities does not take place randomly; rather, most people move within the same city or to neighbouring cities within the region. Locational inertia stems from many sources (family, friends, local knowledge,

\footnotetext{
${ }^{1}$ See Pumain (2006, p. 202): “The proportionality between resident population and inward and outward migratory flows which is derived from the multiplication of the population at the origin by the population at destination in the numerator of the model can be seen as merely an application of a random interaction process".
} 
identity). Thus, one can expect the probability of someone moving between two cities to be dependent on the geographical proximity between two cities.

To include a proximity structure in a simulation model based on the Simon logic of stochastic growth, one should also include intra-firm and intra-city mobility (the diagonal of a flow matrix). Obviously, these flows are characterised by the highest degree of organizational and geographical proximity, respectively. Entrepreneurs who stay within the firm or within the city also move, yet at the shortest distance possible. Once two proximity dimensions are introduced in the model, one can dispense with parameters $q$ and $q^{*}$ and $p$ and $p^{*}$ and replace these by a single organizational proximity parameter controlling the bias to move to a firm at a particular organizational distance, and a single geographical parameter controlling the bias to move to a location at a particular geographical distance.

Empirically, proximity can be introduced in empirical estimations of people flows between firms and between cities. One way to model such flows is by using spatial interaction models (Tinbergen 1962; Wilson 1970). In such models, the strength of flows between two entities is determined by the size of two entities (MASS), and a vector of proximities. Following our two proximity dimensions (organizational and geographical) defined above, organizational and geographical proximity can be introduced in the model to specify the probability that an entrepreneur who leaves a firm chooses for a particular firm and a particular city (possibly the same firm and the same city (s)he already worked in). Organizational proximity $(\mathrm{OP})$ between firms can be expected to increase the probability of labour mobility between two firms (IFIRMS), and geographical proximity (GP) can be expected to increase the probability of labour migration between two cities (ICITIES). The equations to be estimated are:

$$
\begin{gathered}
\operatorname{IFIRMS}_{i j}=\operatorname{MASS}_{i}^{\alpha_{1}} \operatorname{MASS}_{j}^{\alpha_{2}} \mathrm{OP}_{i j}^{\alpha_{3}}+\varepsilon_{i j}, \\
\text { ICITIES }_{i j}=\operatorname{MASS}_{i}^{\beta_{1}} \operatorname{MASS}_{j}^{\beta_{2}} \operatorname{GP}_{i j}^{\beta_{3}}+\varepsilon_{i j} .
\end{gathered}
$$

Such a model could thus, in a simple manner, replicate the existence of "business groups" that rotate key personnel and "city-regions" as a set of cities within a region with strong labour market linkages.

\subsection{Social Capital}

To view economic growth as an ongoing process of product innovations introduced by entrepreneurs who set up their own product division, allows one to introduce an explicit evolutionary dynamic of social tie formation. With each creation of a new product division, a social tie is created between the parent division and the entrepreneur's new division (Breschi and Lissoni 2003, 2006). This social tie 
stems from the shared history of employer and former employee. A shared history here is defined as having worked within the same product division.

One can now understand the set of social ties of a product division as the "social capital" of a division. The amount of social capital is thus a function of the number of previous employees who have set up a new product division. As social capital gives a division access to previous employees, social capital can be thought of as a channel for knowledge spillovers. In a stochastic growth framework, differences in social capital among product divisions implies that firm growth and urban growth are no longer random, but positively dependent on the social capital of its divisions. If a firm or city harbours divisions with a high amount of social capital, the probability that these divisions will generate new entrepreneurs is consequently higher as well. ${ }^{2}$ Because entrepreneurs are biased to set up their product divisions is the firm and/or city of origin, firms and cities with more social capital will grow faster. As the amount of social capital depends on previous growth events, firm growth and city growth are self-reinforcing.

A theory as outlined above, would provide an alternative explanation for endogenous growth and increasing returns to scale different from the one proposed by Krugman (1991) based on economies in production. Such an explanation is compatible with the argument by Boschma and Frenken (2006) that endogenous growth stems from recombination if one assumes that social capital supports the recombination of knowledge residing in different people.

So far, we have only assumed that organizational and geographical proximity matter in that it biases mobility decisions towards more proximate organizations. However, one can also assume that the "quality" of social capital is higher when social ties between parent firm and previous employees are organizational and geographically proximate, since social ties are easier to maintain within organizations and between similar organizations, and within cities or between proximate cities. This means that the probability of a product division generating an entrepreneur becomes not only dependent on the number of its social ties but also its quality.

Importantly, the joint effect of organizational and geographical proximity of the quality of social ties is expected to reflect substitutability (Boschma 2005; Ponds et al. 2007). When the entrepreneur sets up a business within the parent firm, organizational proximity is maximum. As a consequence, the social ties with the previous product division can be easily maintained even at large distance. This allows multi-locational firms to exploit their innovations at the best location without losing too much "social capital" involved in the relation between entrepreneur and his/her previous division. When the entrepreneur decides to remain in the city of origin, (s)he can easily maintain the social ties between the parent division even if it leaves the firm. This allows cities to exploit innovations in different organizational formats while profiting from the social capital involved in the

\footnotetext{
${ }^{2}$ Put differently, the probability of a product division producing a new entrepreneur who sets up his or her own product division is proportional to the number of previous employees who set up an own product division, an example of preferential attachment where the probability that a node acquires a new link is proportional to the node's degree (Barabási and Albert 1999).
} 
relation between entrepreneur and his/her previous division. It thus provides us with a simple logic of why cities and multi-locational firms can be advantageous loci of growth.

Similarly, such substitution effects can exist when entrepreneurs move to similar organizations in "business groups" (allowing them to migrate over larger distance) and to nearby cities in "city-regions" (allowing them to move to different firms). As for multi-locational firms, business groups allow for the exploitation of innovations at different locations without losing too much social capital. And, city-regions allows, as do cities, for the exploitation of innovation in different organizational format while still providing sufficient geographical proximity to support social capital. Thus, both forms of proximity are expected to contribute to the probability of innovation, yet their combined effect will be less than the sum of their effect separately reflecting proximities are substitutes.

\subsection{Concluding Remarks}

The framework proposed here builds on the general framework laid down by Frenken and Boschma (2007). Our perspective combines industrial dynamics and urban growth in a "proximity" perspective. Empirically, this approach can rely on traditional spatial interaction equations/methodologies. Theoretically, it would allow a further extension of the role of multi-locational firms (facilitating the maintenance of social capital between previous colleagues over large distance) and multi-organizational cities (facilitating the maintenance of social capital between previous colleagues between different firms). By doing so, the now popular concepts of "network society" (Castells 1996), "global city regions" (Scott 2001) and "global pipelines and local buzz" (Bathelt et al. 2004) can be further elaborated analytically and analysed systematically using data on labour mobility and labour migration.

\section{References}

Arthur WB (1989) Competing technologies, increasing returns, and lock-in by historical events. Econ J 99:116-131

Barabási A-L, Albert R (1999) Emergence of scaling in random networks. Science 286:509-512

Bathelt H, Malmberg A, Maskell P (2004) Clusters and knowledge: Local buzz, global pipelines and the process of knowledge creation. Prog Hum Geogr 28:31-56

Batty M (2005) Cities and complexity. Understanding cities with cellular atomata, agent-based models, and fractals MIT Press, Harvard, MA

Boschma RA (2004) The competitiveness of regions from an evolutionary perspective. Reg Stud 38(9):1001-1014

Boschma RA (2005) Proximity and innovation. A critical assessment. Reg Stud 39(1):61-74 
Boschma RA, Frenken K (2006) Why is economic geography not an evolutionary science? Towards an evolutionary economic geography. J Econ Geogr 6(3):273-302

Breschi S, Lissoni F (2003) Mobility and social networks: Localised knowledge spillovers revisited. CESPRI Working Paper 142. http://www.cespri.unibocconi.it/, forthcoming in the Annales d'Economie et de Statistique

Breschi S, Lissoni F (2006) Mobility of inventors and the geography of knowledge spillovers. New evidence on US data. CESPRI Working Paper 184. http://www.cespri.unibocconi.it/

Castells M (1996) The rise of the network society. Blackwell, Oxford

David PA (1985) The economics of QWERTY. Am Econ Rev (Papers and Proceedings) 75:332-337

Duranton G, Puga D (2004) Micro-foundations of urban agglomeration economies. In: Henderson JV, Thisse JF (eds) Handbook of regional and urban economics, 1st ed., vol 4. Elsevier: Amsterdam, pp 2063-2117

Frenken K, Boschma RA (2007) A theoretical framework for evolutionary economic geography: industrial dynamics and urban growth as a branching process. J Econ Geogr 7(5):635-649

Krugman PR (1991) Increasing returns and economic geography. J Polit Econ 99(3):483-499

Ponds R, van Oort FG, Frenken K (2007) The geographical and institutional proximity of research collaboration. Pap Reg Sci 86:423-443

Pumain D (2006) Alternative explanations of hierarchical differentiation in urban systems. In: Pumain D (ed.) Hierarchy in natural and social sciences. Springer, Dordrecht, pp 169-222

Scott AJ (2001) Global city-regions. Trends, theory, policy. Oxford University Press, Oxford

Simon HA (1955) On a class of skew distribution functions. Biometrika 42(3-4):425-440

Tinbergen J (1962) The world economy. Suggestions for an international economic policy. Twentieth Century Fund, New York, NY

Wilson AG (1970) Entropy in urban and regional modelling. Pion, London

Zipf G (1949) Human behavior and the principle of least effort. Addison-Wesley, Cambridge MA 